\title{
Treatment of isolated ascending aortic aneurysm by off-pump epiaortic wrapping is safe and durable
}

\author{
Felice Pecoraro*, Masami Shingaki, Johnny Steuer, Lyubov Chaykovska, Zoran Rancic, Alberto Weber, \\ Thi Dan Linh Nguyen-Kim, Dominique Bettex, Frank J. Veith and Mario Lachat
}

Clinic for Cardiovascular Surgery, University Hospital Zurich, Zurich, Switzerland

* Corresponding author. Via L. Guffrè 5, 90100 Palermo, Italy. Tel: +39-328-2141849; fax: +39-091-6552648; e-mail: felicepecoraro@libero.it (F. Pecoraro).

Received 19 October 2015; received in revised form 17 February 2016; accepted 8 March 2016

\begin{abstract}
OBJECTIVES: Isolated ascending aortic aneurysm (iAA) is usually treated by open graft repair requiring sternotomy, cardiopulmonary bypass (CPB) and cardioplegia. This approach carries significant mortality in older patients or those presenting with comorbidities. We report an original series of patients presenting with iAA and treated with epiaortic wrapping by using a synthetic mesh. This less invasive aortic repair technique allows reducing the aortic diameter to a predefined value and is performed without CPB.
\end{abstract}

METHODS: Data from patients presenting with an iAA and treated with the wrapping technique (WT) by polypropylene/polyester mesh from November 2006 to July 2015 were collected. The end-points that were analysed included maximal aortic transverse diameter, perioperative mortality and morbidity, survival, freedom from reinterventions and aortic valve function during follow-up. The maximal aneurysm transverse diameter was analysed based on contrast-enhanced computed tomography (CTA) or magnetic resonance (MR) performed preoperatively, and during the follow-up.

RESULTS: The off-pump WT was used in 33 cases with no perioperative mortality. The median radiological follow-up was 33.47 (range: 1106) months. Overall, the WT achieved a 30\% diameter reduction. The mean preoperative and postoperative ascending aortic transverse diameter was $5.5 \mathrm{~cm}$ [standard deviation (SD): 0.6 ] and $3.7 \mathrm{~cm}$ (SD: 0.30$)$, respectively $(P=0.001)$. In addition, CTA or MR follow-up showed stable diameters at the level of the aortic root and the distal ascending aorta. No death occurred during the follow-up. At 5 years, the estimated freedom rate from reinterventions of the aortic root and ascending aorta was $94 \%$.

CONCLUSIONS: This series shows that the WT with a polypropylene/polyester mesh allows safe off-pump treatment of patients with iAA. Mid- and long-term results are promising. This technique could be an attractive alternative, especially for patients unfit for aortic surgery with $\mathrm{CPB}$ and cardioplegia.

Keywords: Off-pump • Ascending aorta $\cdot$ Graft repair $\cdot$ Mesh (polypropylene/polyester) $\cdot$ Wrapping girdling $\cdot$ Aortic valve insufficiency

\section{INTRODUCTION}

Ascending aortic replacement is one of the most frequent open thoracic aortic procedures [1]. Isolated ascending aortic aneurysm (iAA) is usually treated by open graft replacement and cardiopulmonary bypass (CPB), cardioplegic arrest and eventually hypothermic circulatory arrest. Despite technical and management improvements, significant mortality and morbidity are reported especially in old and polymorbid patients [2]. So far, there is, to our knowledge, no report about a consecutive series of patients with iAA who were treated off-pump with an epiaortic polypropylene/polyester mesh using the wrapping technique (WT).

\section{PATIENTS AND METHODS}

This was a retrospective analysis of patients presenting with an iAA managed by way of the WT with a polypropylene/polyester mesh between November 2006 and July 2015. The indications for iAA repair with the WT were: increased risk associated with conventional open aortic repair, iAA with maximal aortic diameter of $\leq 70 \mathrm{~mm}$ and $\mathrm{iAA}$ originating distal to the sinotubular junction and ending proximally or just at the origin of the brachiocephalic trunk (BCT). Rapid growth and/or a family history of aortic rupture and/or dissection justified treatment even in patients with an ascending aortic diameter $<5 \mathrm{~cm}$. The presence of severe or diffuse plaques or thrombus within the aneurysm and/or severe aortic valve incompetence were contraindications for the WT repair.

Aortic disease extension and quality were assessed on preoperative computed tomography $(\mathrm{CT})$ or magnetic resonance (MR) imaging scan and echocardiography in all cases. Before discharge, all patients were followed by postoperative CT scan or MR and transthoracic echocardiogram with respect to the aortic root and the whole ascending aorta. 
Data were collected in the clinical information system of the University Hospital of Zurich (KISIM 4.901; Dendrite, Dendrite Clinical System, Henley-on-Thames, UK) and were analysed retrospectively in August 2015. Demographic and clinical data were collected including the EuroSCORE II risk model [3]; outcome measures included perioperative mortality and morbidity, maximal aortic transverse diameter (TD), survival, freedom from cardiovascular reinterventions and aortic valve function during follow-up. Informed consent about the procedure itself and the anonymous data collection and analysis was obtained from all patients. Follow-up consisted of clinical examination, CTA or MR and echography performed yearly. The median follow-up was 33.47 (range: 1-106) months.

\section{Statistical analysis}

Means and standard deviation (SD) or median and range were reported for parametric data; and absolute values and percentages for non-parametric data. Differences in preoperative and postoperative maximal aortic TD were assessed using the $t$-test. Kaplan-Meier curves were used to estimate survival and freedom from cardiovascular reinterventions. Statistical significance was considered at $P<0.05$. For Kaplan-Meier curves, the confidence interval $(\mathrm{Cl})$ and standard error exceeding $10 \%$ were reported. Statistical analysis was performed using SPSS 16.0 (SPSS, Inc., Chicago, IL, USA).

\section{Technique}

After full median sternotomy, the ascending aorta was dissected and exposed from the sinus to the origin of the BCT or eventually to the left common carotid artery. Before its use, the polypropylene or polyester mesh was marked in accordance with the predetermined size with a sterile marker (Fig. 1A). The final transverse aortic circumference was calculated preoperatively by multiplying the intended aortic diameter by 3.14 , thereby determining the width of the polypropylene/polyester mesh to be wrapped around the aorta. For example, if the planned final aortic diameter was $35 \mathrm{~mm}$, two longitudinal markers at an interval of $(35 \times 3.14=109.9 \mathrm{~mm}$, which was approximated to $11 \mathrm{~cm}) 11 \mathrm{~cm}$ were placed on the mesh. The marked mesh was placed around the ascending aorta (Fig. 1B) and fixed to the posterior aortic wall with two proximal anchoring stitches (Ticron 4.0). These were placed proximally just above the coronary sinuses, after having identified the left and right coronary arteries. The mesh was then sutured, according to the predefined marked lines, with a polypropylene 3.0 running suture (Blalock suture technique) beginning at the sinotubular junction and ending just proximally to the BCT. It is to be noted that this first running suture line did not concern the aortic wall, but just the polypropylene/polyester mesh (Fig. 2A). At completion of this first running suture line, the blood pressure was lowered while the suture was tightened (Fig. 2B). The fixed polypropylene/polyester mesh was then shaped in length and the procedure completed by a second suture line fixating the mesh to the aortic wall (Fig. 2C). Additional anchoring stitches were placed distally close to the origin of the BCT and in the concavity of the proximal aortic arch (Fig. 2D).

Transoesophageal echocardiography was used in all patients to assess the heart function during the procedure and the impact of the reconstruction on aortic valve function.

\section{RESULTS}

A total of 33 iAA patients with a mean age of 66.8 years (SD: 11) were treated by WT using a polypropylene or polyester mesh. During the same study period, $\sim 130$ cases per year were addressed by open ascending aorta replacement. All the WT cases were performed on an elective basis. Comorbidities and risk factors are reported in Table 1. The mean EuroSCORE II was $12.36 \%$. In 8 (24\%) patients, a moderate aortic valve insufficiency, due to impairment of the normal sinotubular geometry was observed on preoperative echocardiography. Another patient had a mild-severe aortic valve stenosis. Ten patients (30\%) presented with additional aortic disease apart from iAA. Two of these patients were treated before the WT, 4 were treated after the WT and 4 patients are under radiological observation (Table 2).

The preoperative iAA mean maximal TD was $5.5 \mathrm{~cm}$ (SD: 0.6). In $29(88 \%)$ patients, the ascending aorta was wrapped with a polypropylene mesh (Prolene; Ethicon, USA); in the remaining 4 (12\%) cases, performed at the beginning of our experience, a polyester mesh (Mersilene; Ethicon) was used.

There was no early or late mortality. Three patients (9\%) had early postoperative complications. One patient suffered transient anterior spinal cord ischaemia during a postoperative septic shock managed by medical therapy. Another patient had a transient cerebral ischaemic attack due to an episode of postoperative
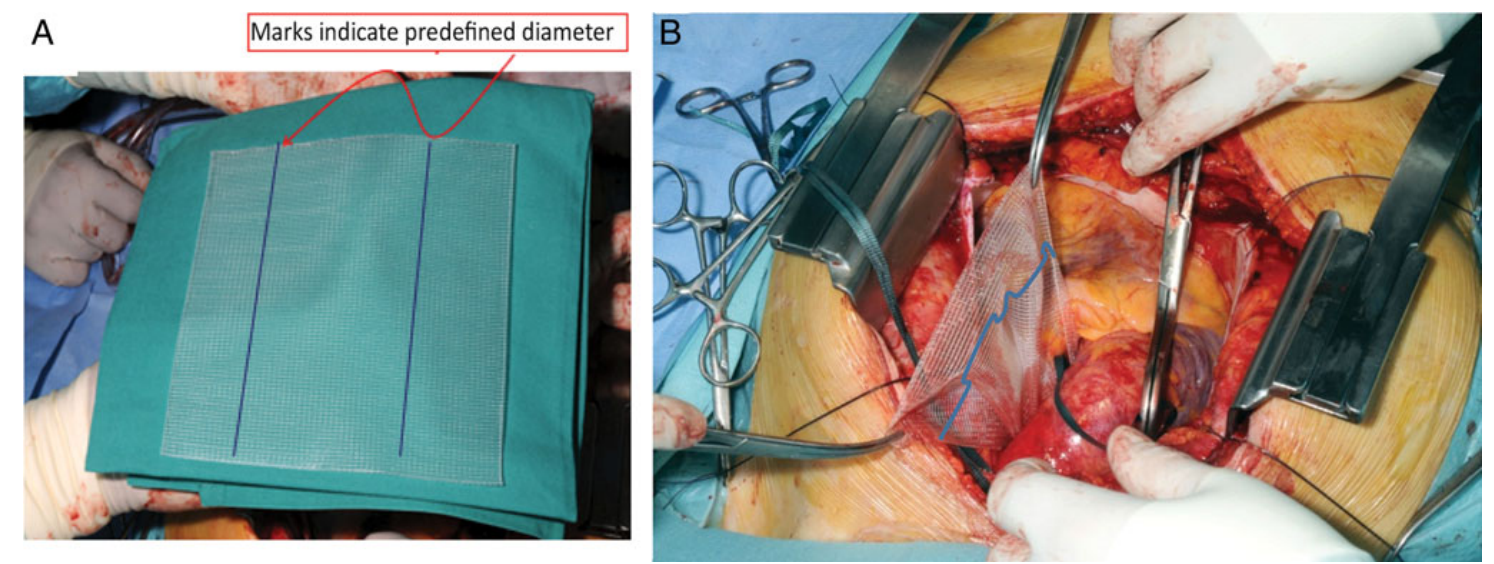

Figure 1: Technique: (A) Polypropylene/polyester mesh marked with a permanent marker before its implantation. (B) Polypropylene/polyester mesh after its passage behind the aorta. 

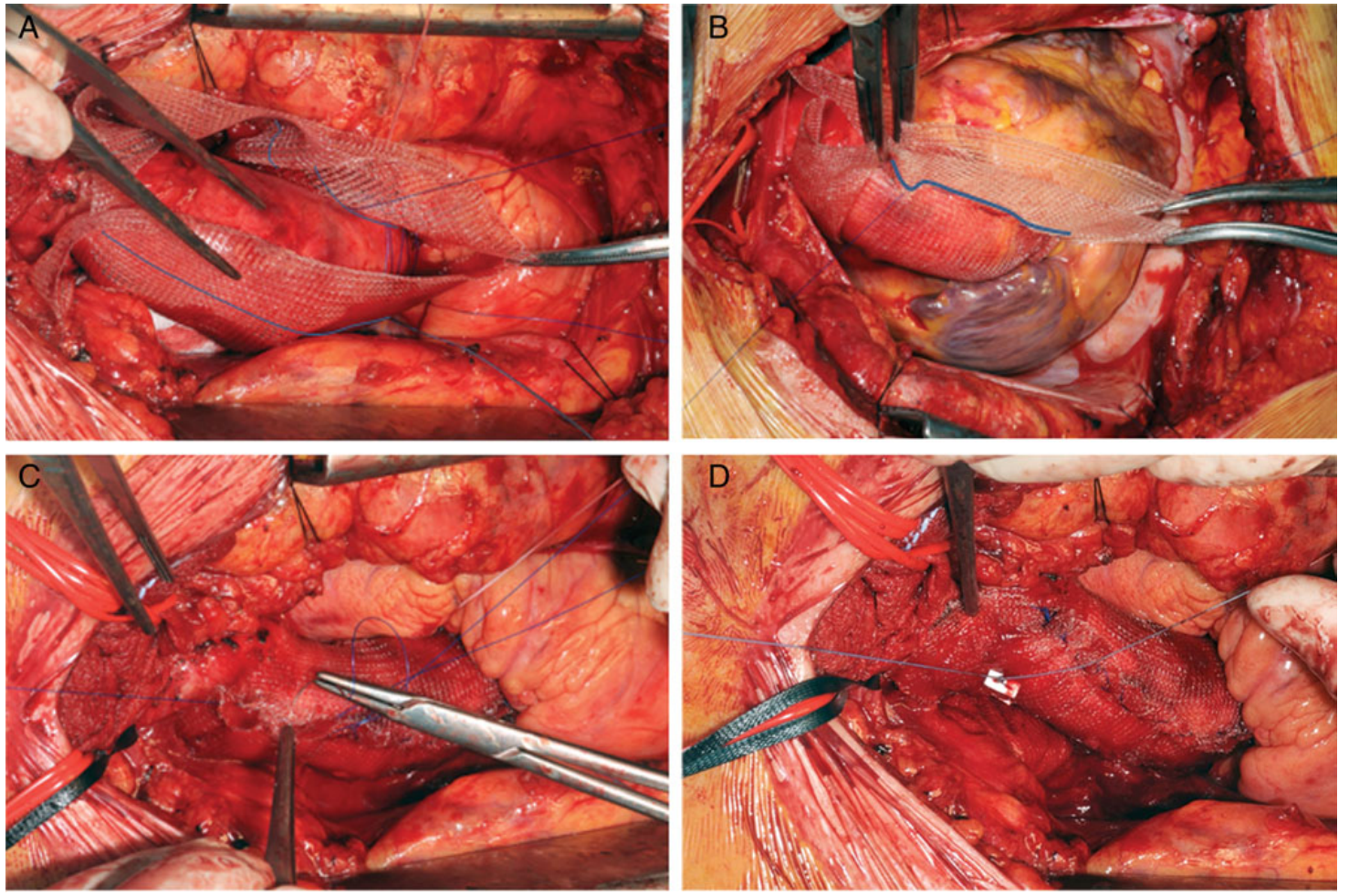

Figure 2: Intraoperative findings. (A) Polypropylene/polyester mesh longitudinal suture (Blalock suture technique). (B) Blalock suture tightening while lowering blood pressure. (C) Second suture row fixing the polypropylene/polyester mesh to the aortic wall. (D) Distal stitch placement below the origin of the brachiocephalic trunk.

Table 1: Demographic and clinical preoperative data

$\begin{array}{lc}\text { Number of patients } & 33 \\ \text { Mean age (years) } & 67 \\ \text { Over 70 years (\%) } & 14(42) \\ \text { Female (\%) } & 16(49) \\ \text { Hypertension (\%) } & 28(85) \\ \text { Pulmonary disease (\%) } & 21(64) \\ \text { Cardiac disease (\%) } & 19(58) \\ \text { Aortic valve insufficiency } & 8(24) \\ \text { Aortic valve stenosis } & 1(3) \\ \text { Coronary artery disease } & 10(30) \\ \text { Moderate aortic insufficiency (\%) } & 8(24) \\ \text { Lipid disorder (\%) } & 17(52) \\ \text { Peripheral arterial disease (\%) } & 8(24) \\ \text { Cancer (\%) } & 4(12) \\ \text { Cerebrovascular disease (\%) } & 4(12)\end{array}$

cardiac ventricular fibrillation treated medically. The third complication was a sternal bleeding requiring surgical revision. In the 8 cases exhibiting moderate aortic valve insufficiency, intraoperative transoesophageal echocardiography showed a normalization of the valve function after completion of the WT with a polypropylene/polyester mesh. In the other 25 patients with normal heart function, no changes of valve morphology and/or function was observed.

The postoperative ascending aortic mean maximal TD was $3.7 \mathrm{~cm}$ (SD: 0.3), implying a mean reduction of $30 \%(P=0.001)$.

The mean hospital length of stay was 8 days (SD: 1.9) and the mean intensive care unit stay was 1.3 days (SD: 1.6). Predischarge $\mathrm{CT}$ showed no significant aortic wall infolding.
Table 2: Associated aortic pathologies and surgery

\begin{tabular}{|c|c|c|}
\hline Pt ID & $\begin{array}{l}\text { Associated aortic } \\
\text { disease }\end{array}$ & Surgery \\
\hline 3 & $\begin{array}{l}\text { TAAA } \\
\text { SRAA }\end{array}$ & None \\
\hline 9 & TAAA Crawford I & $\begin{array}{l}\text { Before ascending WT } \\
\text { (1) Proximal open thoracic aortic repair } \\
\text { (2) Complete renovisceral debranching } \\
\text { (3) TEVAR }\end{array}$ \\
\hline 10 & TAAA Crawford II & $\begin{array}{l}\text { After ascending WT } \\
\text { (1) Complete renovisceral debranching } \\
\text { and TEVAR up to T8 } \\
\text { (2) TEVAR up to Zone } 3 \text { and periscope LSA }\end{array}$ \\
\hline 11 & Arch aneurysm & $\begin{array}{l}\text { Before ascending WT } \\
\text { (1) Aortic valve and partial ascending } \\
\text { aortic replacement }\end{array}$ \\
\hline 12 & TAAA Crawford IV & None \\
\hline 15 & TAAA Crawford II & None \\
\hline 19 & Arch aneurysm & None \\
\hline 24 & $\begin{array}{l}\text { TAA } \\
\text { AAA }\end{array}$ & $\begin{array}{l}\text { After ascending WT } \\
\text { (1) Complete renovisceral debranching } \\
\text { (2) TEVAR }\end{array}$ \\
\hline 25 & $\begin{array}{l}\text { Arch aneurysm } \\
\text { TAAA Crawford II }\end{array}$ & $\begin{array}{l}\text { After ascending WT } \\
\text { (1) Ileo-femoral conduit } \\
\text { (2) Carotid-subclavian bypass left } \\
\text { (3) TEVAR Zone } 0-4\end{array}$ \\
\hline 27 & AAA & $\begin{array}{l}\text { After ascending WT } \\
\text { (1) EVAR }\end{array}$ \\
\hline
\end{tabular}

Pt ID: patient identification number; TAAA: thoraco-abdominal aortic aneurysm; TAA: thoracic aortic aneurysm; SRAA: suprarenal aortic aneurysm; AAA: abdominal aortic aneurysm; TAVI: transcatheter aortic valve implantation; TEVAR: thoracic endovascular aneurysm repair; EVAR: endovascular aneurysm repair (abdominal); LSA: left subclavian artery. 

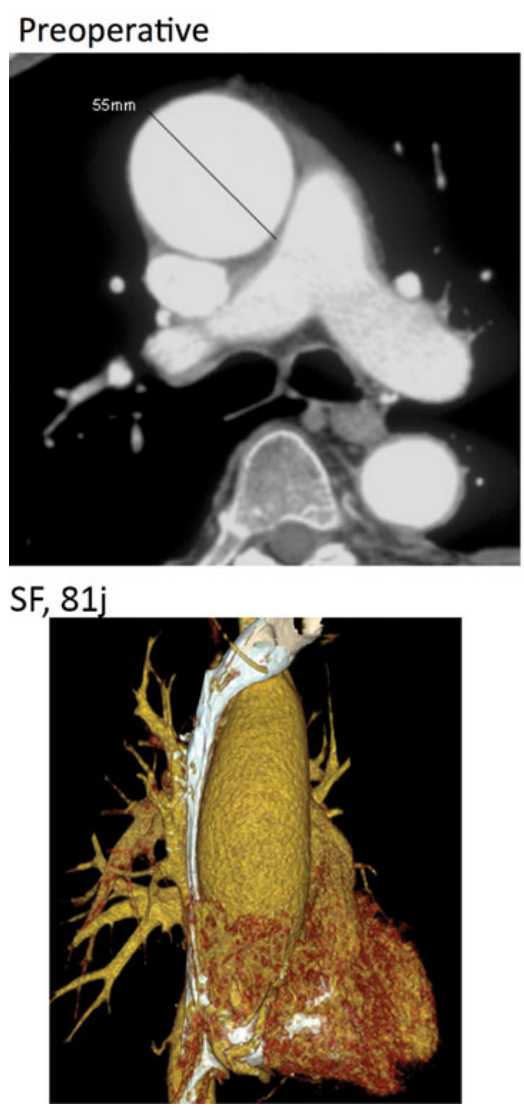

Postoperative
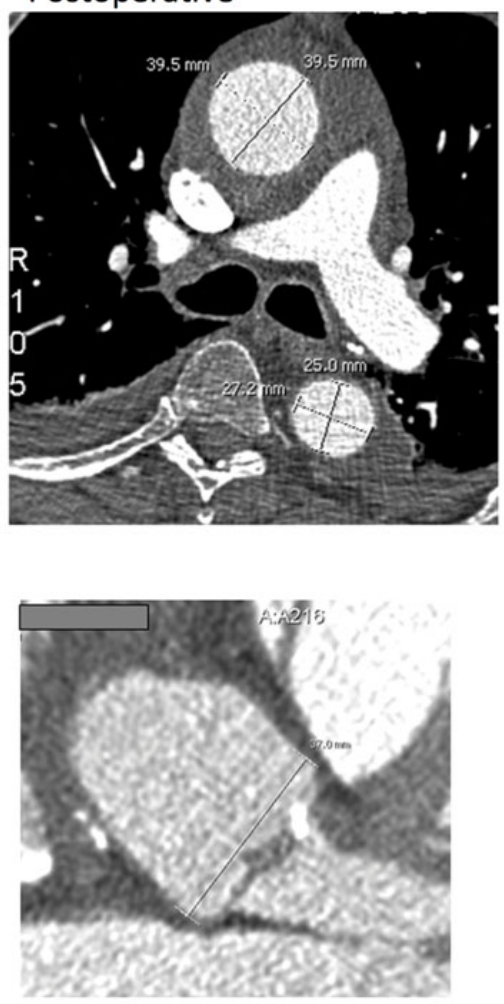

4 years follow-up
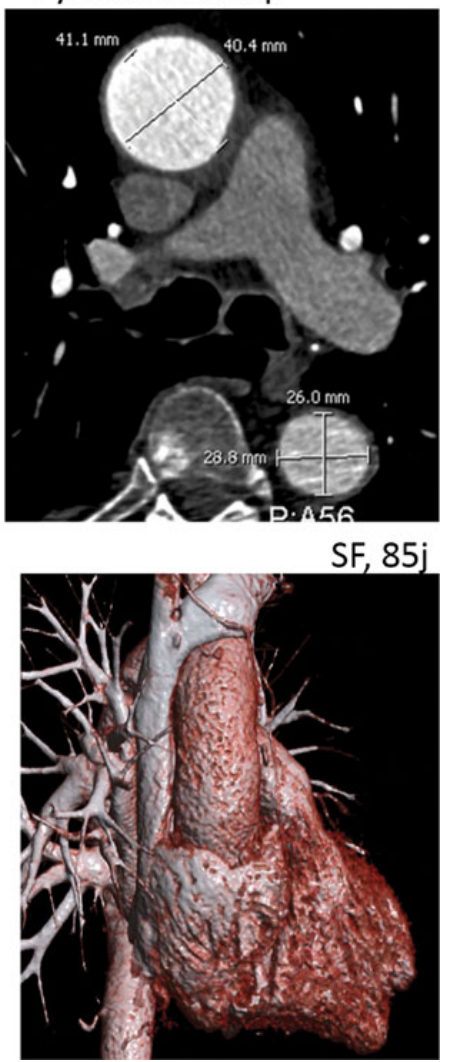

Figure 3: CT findings. (A) Preoperative $5.5 \mathrm{~cm}$ ascending aortic aneurysm. (B) Ascending aortic postoperative transverse diameter measurement. (C) Four-year ascending aorta and aortic root transverse diameter measurement showing no significant variation in size with postoperative findings. CT: computed tomography.

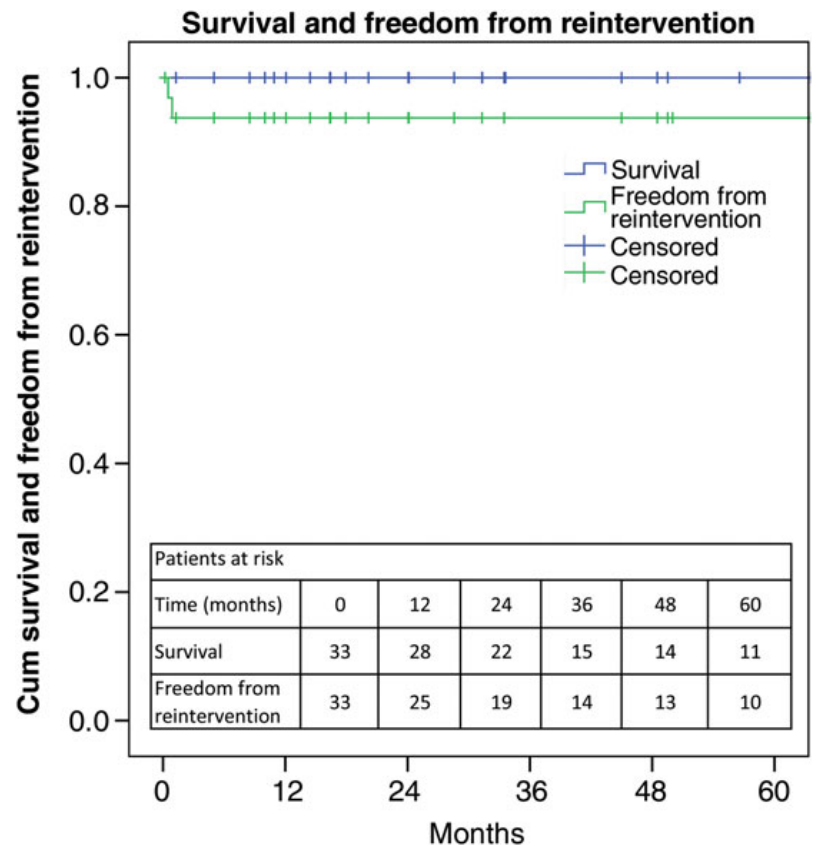

Figure 4: Survival and freedom from reintervention. SE does not exceed $10 \%$ at 5 years for the survival curve (SE: 1.7; Cl: 101-109) and the freedom from reintervention curve (SE: 4.5; Cl: 91-109). SE: standard error; $\mathrm{Cl}$ : confidence interval.

The median follow-up was 33.47 months (range: 1-106 months) with 28,15 and 11 of the 33 patients followed for more than 1, 3 and 5 years, respectively. No patients were lost during the follow-up.
During the follow-up, CT showed no relevant variation in size compared with postoperative measurements performed before discharge, no erosion and no migration (Fig. 3). At 9 months of follow-up, 1 patient underwent trans-femoral transcatheter aortic valve implantation (TAVI) with no complication due to mildsevere aortic valve stenosis. This patient suffered from mild aortic valve stenosis already before the WT operation but, at that time, he refused an open valve repair intervention.

The estimated freedom rate from ascending and aortic root reintervention at 5 years was $94 \%$ (Fig. 4). No death occurred during the follow-up period.

\section{DISCUSSION}

The gold standard for ascending aortic aneurysm treatment is open graft replacement and in large series from high-volume centres, the reported perioperative mortality can be as low as $0-8 \%$ [4]. However, higher mortality and morbidity rates are observed in the elderly and/or patients with multiple comorbidities $[2,4,5]$. The Achilles tendons of the standard ascending replacement technique are $\mathrm{CPB}$, cross-clamping of the aorta and eventually hypothermic circulatory arrest, which are associated with higher risks, especially of permanent neurological injury [6]. Preservation of the native aortic tissue and external reinforcement is not a new concept [7]. Reinforcement with an epiaortic polypropylene or polyester mesh was introduced by Ake Senning in the 1960s and reported in 1982 by Egloff. In this historical series, most patients had ascending aortic aneurysm combined with severe 
aortic valve stenosis (post-stenotic aortic dilatation). The mean follow-up covered a 45-month period and from the 17 patients treated with WT, 2 were reoperated during follow-up because of net displacement [8]. In a meta-analysis and systematic review of 722 patients treated with wrapping of the ascending aorta concomitantly with another cardiac procedure(s) and performed with cardioplegic arrest, Plonek reported similar results with ascending aortic replacement at a mean follow-up of 62 months. Both these studies, as well as a more recent report [9], highlighted the importance of wrap safe anchoring to the aorta in order to avoid net displacement [10]. Also, in our experience, to reduce the risk of such complication, proximal and distal anchoring stitches in association to a second suture line that fixes the mesh to the aortic wall are advocated.

Different WT technique modifications have been reported with or without aortoplasty and with different types of external reinforcement meshes or grafts (Dacron, thin Dacron, polypropylene, polyester) $[6-8,10-13]$. Cohen et al. [13], in a series of 102 patients treated over a 20-year period, showed excellent long-term behaviour of the repaired ascending aorta using a thin Dacron mesh. In that series, proximal aneurysm degeneration occurred in only 2 cases during the long-term follow-up. In all the previously reported series, wrapping was combined with other cardiac procedures requiring $\mathrm{CPB}$.

In the present study, a polypropylene (Prolene; Ethicon) mesh was employed in $88 \%$ of the cases, whereas polyester (Mersilene; Ethicon) was used in $12 \%$ at the beginning of our experience. Both non-resorbable polypropylene and polyester meshes, which to some extent are elastic, adapt perfectly to the aortic wall, which is obviously not the case with a Dacron graft $[9,12]$.

A multibranched mathematical model of the arterial system demonstrated that wrapping and reducing the diameter of the ascending aortic wall with a highly compliant elastic material would shift the pulsatile load from the aortic wall to the wrap and thus increase the functional compliance of the ascending aorta and decrease the cardiac load [14]. Another potential complication of the WT is the erosion of aortic wall due to the wrap $[15,16]$. This was reported with the Dacron graft used to wrap the ascending aorta. It was argued that the Dacron wrinkles could play a role in the development of the aortic erosion due to a direct mechanical action and the lack of elasticity in Dacron [17]. On this basis, we thought that the use of polypropylene or polyester mesh to wrap the ascending aorta could lead to a reduced risk of aortic wall compression atrophy or erosion when compared with Dacron. A study of stress analysis using the finite elements method compared the ascending aortic wall stress in different situations. This study showed that the wrapped aorta had similar stress when compared with a normal aorta and both had lower stress when compared with a moderately dilated aorta, supporting a reduced risk for dissection in a wrapped when compared with a dilated aorta. On these biomechanical bases, the wrapping of the ascending aorta was advocated as a reasonable surgical option in a mildly dilated aorta to prevent aortic dissection [18].

We did not observe any obvious aortic wall plications or infolding after having reduced the aortic diameter by $\sim 30 \%$ with the polypropylene/polyester mesh, neither postoperatively nor during the follow-up. The same findings were observed even for larger (up to $70 \mathrm{~mm}$ ) ascending aneurysms. It was hypothesized that the limited aortic elasticity could proceed to attaining normal behaviour when an external wrap is placed, due to the arterial pressure pushing the aortic wall against the wrap [18]. However, we believe that major reduction ( $>30 \%$ ), especially in larger ascending aneurysms (60-70 mm), could negatively affect this remodelling process.

As reported, the WT has commonly been employed in combination with another cardiac procedure(s), mostly aortic valve replacement $[6,10-13,15,19]$. Our series is different in that it is the first report addressing a consecutive series of patients with iAA undergoing aortic repair without the use of CPB. The early and midterm results achieved in our series of polypropylene/polyester mesh WT patients are very encouraging. The WT allowed a TD reduction of $\sim 30 \%$ that remained stable during the follow-up. The radiological follow-up with CT or RM scan of the 33 patients showed no polypropylene or polyester mesh migration and no modifications of the TD in the aortic root, the ascending aorta or the proximal aortic arch, even in the long term (11 patients with $>5$ years of follow-up). Our mid- and long-term results are similar to those achieved by Cohen et al. [13].

The indication for polypropylene/polyester mesh WT in iAA treatment is probably limited to aneurysms with a maximal TD below $70 \mathrm{~mm}$. In fact, at larger diameters, the aortic wall is very thin and the tissue dissection of the aorta and/or the pulmonary artery might be hazardous. With polypropylene/polyester mesh WT, the risk of plaque disruption and athero-embolization due to aortic clamp application is avoided [20]. However, severe calcifications and/or visible plaques are contraindications for the WT as plaque rupture and embolization may occur while the mesh is tightened around the aorta.

We used the polypropylene/polyester mesh WT initially exclusively for iAA patients with normal aortic valve function. In the meantime, we experienced that the surgical remodelling of the ascending aorta with the WT corrects the sinotubular geometry and eventually the associated valvular dysfunction. We therefore extended with success the WT indication to patients presenting with slight to mild aortic insufficiency if it was related to a geometrical disturbance of the sinotubular junction. The aortic valve function was assessed intraoperatively in all patients by transoesophageal echocardiography before and after the WT intervention. In the eight cases presenting with aortic valve insufficiency before the wrapping operation, the aortic valve function improved or normalized after the WT. Valve function of these patients remained stable during the follow-up. One patient, presenting with mid aortic valve stenosis, required TAVI during the follow-up as part of an intentionally staged procedure.

Moreover, the polypropylene/polyester mesh WT allows extending the applicability of endovascular aneurysm repair to patients presenting with aneurysm or dilatation in Zone zero [21-23]. Obviously, the polypropylene/polyester mesh WT can be applied safely and successfully to treat symptomatic aneurysm [24], but this remains to be confirmed by more experience.

Finally, this technique should be performed only in centres that have access to $C P B$, as conversion to conventional surgery with graft replacement may be required.

\section{CONCLUSION}

The ascending aortic WT with polypropylene/polyester mesh represents a safe alternative to conventional graft repair in selected patients with isolated ascending aneurysm. This holds true also for patients with minor aortic valve dysfunction related to disturbance of the sinotubular junction. Mid- and long-term results are very promising. The primary target populations for this technique are elderly and/or polymorbid patients considered unfit or at high risk 
for ascending aortic surgery with CPB support and cardiac arrest and/or hypothermic circulatory arrest.

\section{Conflict of interest: none declared.}

\section{REFERENCES}

[1] Gillum RF. Epidemiology of aortic aneurysm in the United States. J Clin Epidemiol 1995:48:1289-98.

[2] Okita Y, Ando M, Minatoya K, Tagusari O, Kitamura S, Nakajjma N et al. Early and long-term results of surgery for aneurysms of the thoracic aorta in septuagenarians and octogenarians. Eur J Cardiothorac Surg 1999;16: 317-23.

[3] Nashef SA, Roques F, Sharples LD, Nilsson J, Smith C, Goldstone AR et al. EuroSCORE II. Eur J Cardiothorac Surg 2012;41:734-44; discussion 744-735.

[4] Moon MC, Morales JP, Greenberg RK. The aortic arch and ascending aorta: are they within the endovascular realm? Semin Vasc Surg 2007;20:97-107.

[5] Kazui T, Washiyama N, Muhammad BA, Terada H, Yamashita K, Takinami $\mathrm{M}$. Improved results of atherosclerotic arch aneurysm operations with a refined technique. J Thorac Cardiovasc Surg 2001;121:491-9.

[6] Carrel T, von Segesser L, Jenni R, Gallino A, Egloff L, Bauer E et al. Dealing with dilated ascending aorta during aortic valve replacement: advantages of conservative surgical approach. Eur J Cardiothorac Surg 1991;5:137-43.

[7] Robicsek F. A new method to treat fusiform aneurysms of the ascending aorta associated with aortic valve disease: an alternative to radical resection. Ann Thorac Surg 1982;34:92-4.

[8] Egloff L, Rothlin M, Kugelmeier J, Senning A, Turina M. The ascending aortic aneurysm: replacement or repair? Ann Thorac Surg 1982;34: 117-24.

[9] Bauer M, Grauhan O, Hetzer R. Dislocated wrap after previous reduction aortoplasty causes erosion of the ascending aorta. Ann Thorac Surg 2003; 75:583-4.

[10] Plonek T. A meta-analysis and systematic review of wrapping of the ascending aorta. J Card Surg 2014;29:809-15

[11] Ang KL, Raheel F, Bajaj A, Sosnowski A, Galinanes M. Early impact of aortic wrapping on patients undergoing aortic valve replacement with mild to moderate ascending aorta dilatation. J Cardiothorac Surg 2010;5:58.

[12] Tappainer E, Fiorani V, Nocchi A, Likaj E, Memishaj S, Zogno M. Safe wrapping of the borderline dilated ascending aorta during aortic valve replacement. J Cardiothorac Surg 2007;2:15.

[13] Cohen O, Odim J, De la Zerda D, Ukatu C, Vyas R, Vyas N et al. Long-term experience of girdling the ascending aorta with Dacron mesh as definitive treatment for aneurysmal dilation. Ann Thorac Surg 2007;83:S780-4; discussion S785-790.

[14] Giudici F, Qian Y, O'Rourke M, Avolio A. Simulation of reduction of proximal aortic stiffness by an elastic wrap and effects on pulse pressure. Conf Proc IEEE Eng Med Biol Soc 2012;2012:657-60.

[15] Akgun S, Atalan N, Fazliogullari O, Kunt AT, Basaran C, Arsan S. Aortic root aneurysm after off-pump reduction aortoplasty. Ann Thorac Surg 2010;90: e69-70.

[16] Doyle M, Peeceeyan S, Bonar F, Horton M. Rarefaction of the aorta under Dacron wrap: a rare complication. Interact CardioVasc Thorac Surg 2014; 19:341-3.

[17] Neri E, Massetti M, Tanganelli P, Capannini G, Carone E, Tripodi A et al. Is it only a mechanical matter? Histologic modifications of the aorta underlying external banding. J Thorac Cardiovasc Surg 1999;118:1116-8.

[18] Plonek T, Rylski B, Dumanski A, Siedlaczek P, Kustrzycki W. Biomechanical analysis of wrapping of the moderately dilated ascending aorta. J Cardiothorac Surg 2015;10:106.
[19] Lee $\mathrm{SH}$, Kim JB, Kim DH, Jung $\mathrm{SH}$, Choo SJ, Chung $\mathrm{CH}$ et al. Management of dilated ascending aorta during aortic valve replacement: valve replacement alone versus aorta wrapping versus aorta replacement. J Thorac Cardiovasc Surg 2013;146:802-9.

[20] Harringer W. Capture of particulate emboli during cardiac procedures in which aortic cross-clamp is used. International Council of Emboli Management Study Group. Ann Thorac Surg 2000;70:1119-23.

[21] Lachat M, Rancic Z, Frauenfelder T, Pfammatter T, Veith FJ, Mayer D. Viabahn debranching of supra-aortic branches. In: Greengalgh RM (ed). Vascular and Endovascular Controversies Update. London, United Kingdom, 2009, 146-54.

[22] Pecoraro F, Pfammatter T, Lachat M, Mayer D, Veith F, Rancic Z. A new off-pump hybrid open and endovascular repair to treat ductus Botalli and ascendens aneurysms. Vasc Endovasc Surg 2012;46:172-5.

[23] Gelpi G, Vanelli P, Mangini A, Danna P, Contino M, Antona C. Hybrid aortic arch repair procedure: reinforcement of the aorta for a safe and durable landing zone. Eur J Vasc Endovasc Surg 2010;40:709-14.

[24] Demondion P, Ramadan R, Azmoun A, Raoux F, Angel C, Nottin R et al. Aortic wrapping for Stanford type A acute aortic dissection: short and mid-term outcome. Ann Thorac Surg 2014;97:1590-6.

eComment. Ascending aorta wrapping with minimally invasive approaches

Authors: Didem M. Oztas, Cagla Canbay, Murat Ugurlucan and Enver Dayioglu Cardiovascular Surgery, Istanbul University Medical Faculty, Istanbul, Turkey doi: 10.1093/icvts/ivw166

(C) The Author 2016. Published by Oxford University Press on behalf of the European Association for Cardio-Thoracic Surgery. All rights reserved.

We read with great interest the article by Pecoraro et al. The technique seems a safe alternative to open graft repair especially in old and polymorbid patients when compared with conventional aortic replacement with cardiopulmonary bypass [1]

The authors' study population includes patients with certain comorbidities carrying increased risks for conventional aortic replacement. In the era of minimally invasive surgery, it is not difficult to reach the ascending aorta with a mini-sternotomy or thoracotomy. It is well documented that minimally invasive techniques reduce operative trauma and length of stay in the cardiac intensive care unit [2]. In addition, mini sternotomy decreases blood transfusion requirements, ventilation times and length of hospital stay [3]. Minimally invasive techniques are even easier when there is no need for concomitant procedures and sole ascending aortic exposure is required.

We congratulate the authors for their successful management strategy in such a high-risk patient population; however, it would be more informative if the authors could kindly comment why they have not preferred minimally invasive approaches when the aim was only aortic wrapping.

Conflict of interest: none declared.

\section{References}

[1] Pecoraro F, Shingaki M, Steuer J, Chaykovska L, Rancic Z, Weber A et al. Treatment of isolated ascending aortic aneurysm by off-pump epiaortic wrapping is safe and durable. Interact CardioVasc Thorac Surg 2016;23:286-91.

[2] Khoshbin E, Prayaga S, Kinsella J, Sutherland FW. Mini-sternotomy for aortic valve replacement reduces the length of stay in the cardiac intensive care unit: meta-analysis of randomised controlled trials. BMJ Open 2011;1: e000266.

[3] Neely RC, Boskovski MT, Gosev I, Kaneko T, McGurk S, Leacche M et al. Minimally invasive aortic valve replacement versus aortic valve replacement through full sternotomy: the Brigham and Women's Hospital experience. Ann Cardiothorac Surg 2015;4:38-48. 